\title{
Renal Vein Thrombosis and Membranous Nephropathy - Report of 2 Cases
}

\author{
ELIZABETH F DAHER, ${ }^{1}$ GERALDO B SI LVA J UNI OR, ${ }^{1}$ GABRI ELA S GALDI NO, ${ }^{1}$ DENI SLENE S EDUARDO, ${ }^{1}$ TATIANA P \\ WANDERLEY, ${ }^{1}$ GERMI SON S LOPES ${ }^{1}$
}

\begin{abstract}
Patients with nephrotic syndrome presents a high risk of arterial and venous thrombosis, mainly deep vein thrombosis and renal vein thrombosis (RVT). We describe two cases of patients with diagnosis of membranous nephropathy and RVT. The first patient was 32 years, male, and admitted with nephrotic syndrome. Laboratory tests showed urea $16 \mathrm{mg} / \mathrm{dL}$, creatinine $0.9 \mathrm{mg} / \mathrm{dL}$; proteinuria $17 \mathrm{~g} /$ day. Abdominal ultrasound evidenced obstruction of right and left renal veins and left inferior vena cava. Renal biopsy was compatible with membranous nephropathy. The second patient, a 27 years old male was admitted with nephritic syndrome. Laboratory tests at admission showed urea $25 \mathrm{mg} / \mathrm{dL}$; creatinine $1.1 \mathrm{mg} / \mathrm{dL}$; $24 \mathrm{~h}$ proteinuria $3.86 \mathrm{~g}$, abdominal ultrasound showed endoluminal obstruction of left renal vein and increased size left kidney. Renal biopsy showed membranous nephropathy. RVT is not common in patients with nephrotic syndrome, and it is more frequent in membranous nephropathy. Treatment includes intravenous anticoagulant followed by oral drugs. Prophylaxis in nephritic patients is controversial.
\end{abstract}

Keyword: Nephrotic syndrome, Thrombosis, Membranous glomerulonephritis, Blood coagulation

\section{Introduction}

Patients with nephrotic syndrome have a higher risk for venous and arterial thrombosis, mainly deep vein thrombosis (DVT) and renal vein thrombosis (RVT). The prevalence is estimated in $5 \%$ and $60 \%$, mainly in patients with membranous nephropathy. ${ }^{1-3}$

The prevalence of pulmonary embolism and DVT in patients with nephritic syndrome is based on case series. The prevalence of DVT in some cohorts was higher than the prevalence of RVT and in some series the prevalence of RVT was higher ${ }^{1-16}$. The presence of assymptomatic pulmonary embolism and RVT were also described in nephrotic syndrome. ${ }^{8,9,17}$ The relative higher prevalence of RVT and its association with pulmonary embolism suggests that RVT was the origin of embolli in these patients with nephrotic syndrome. ${ }^{18-20}$
RVT can be unilateral or bilateral; it can extend through inferior vena cava and can be associated with pulmonary embolism. The risk of thrombosis is proportional to the severity of nephritic syndrome, mainly with serum levels of albumin lower than $2 \mathrm{~g} / \mathrm{dL}$ and proteinuria higher than $10 \mathrm{~g} /$ day. ${ }^{1,2}$ The majority of RVT cases are insidious and assymptomatic, without a clear association with proteinuria increase or renal function worsening. This paper describes two cases of membranous nephropathy complicated with RVT.

\section{Case Reports}

\section{Case 1}

A 32 years-old man was admitted with history of edema for three months, initially in lower limbs, that progressed to perineal region and abdomen, associated with oliguria. He also referred weight loss, associated with muscular pain and asthenia. At admission he had a good general appearance,
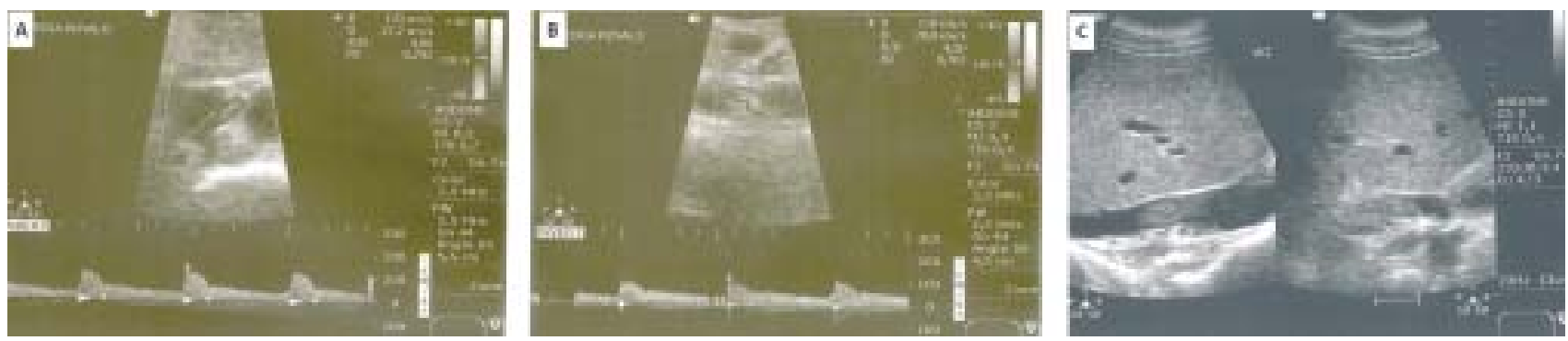

Fig-1: Ultrasound with doppler showing partial obstruction in right renal vein (A), left renal vein (B) and adjacent inferior vena cava (C).

1. Department of Internal Medicine, School of Medicine, Federal University of Ceara. Fortaleza, Ceara, Brazil

Correspondence: Geraldo B Silva Junior, Department of Internal Medicine, School of Medicine, Federal University of Ceara. Fortaleza, Ceara, Brazil, E-mail: geraldobezerrajr@yahoo.com.br 
and the physical examination was unremarkable, unless for the presence of tender abdomen, with edema in abdominal wall and lower limbs. Laboratory tests at admission showed Hemoglobin 13.8g/dL; White blood count 8330/. $\mathrm{mm}^{3}$; INR 0.86; Urea 16mg/dL; Creatinine 0.9mg/dL; $\mathrm{K}^{+} 3.9 \mathrm{mEq} / \mathrm{L} ; \mathrm{Na}^{+}$ 144mEq/L; C3 129mg/dL; C4 48mg/dL; albumin 2g/dL; proteinuria de 24h 15g/day; negative antinuclear antibodies (ANA). Viral serologies were negative. An abdominal ultrasound with Doppler showed increased size kidneys, with increased echogenicity, obstruction of right renal vein, left renal vein and adjacent portion of inferior vena cava, compatible with renal vein thrombosis (Figure 1).

A renal biopsy was performed. At optic microscopy it was observed global thickening of basal membrane and the presence of spikes. Direct immunofluorescence found deposits of IgG, C3d and kappa and lambda chains, compatible with diagnosis of membranous nephropathy. Treatment with cyclosporine $100 \mathrm{mg}$ twice a day was started. After 6 months the laboratory tests showed creatinine $0.9 \mathrm{mg} /$ $\mathrm{dL}$, urea $11 \mathrm{mg} / \mathrm{dL}$ and proteinuria of $4.87 \mathrm{~g} / \mathrm{day}$. The hematology consultant suggested anticoagulation with warfarin $7.5 \mathrm{mg}$ /day during the first 3 months, followed by a decrease for $5 \mathrm{mg} /$ day during 9 months. Anticardiolopin test was negative.

\section{Case 2}

A 27 years-old man was admitted with complaints of left lumbar pain that irradiated to left paravertebral region, abdomen and left testis for four weeks. He also noted increase in testis size. After two weeks of the initial symptoms he presented dark urine and lower limbs edema. At physical examination he presented only flank pain at palpation and percussion and increased scrotal bursa. Laboratorial tests at admission showed Hemoglobin $12.9 \mathrm{~g} / \mathrm{dL}$; White blood count $7230 / \mathrm{mm}^{3}$; platelets $294000 / \mathrm{mm}^{3}$; urea $25 \mathrm{mg} / \mathrm{dL}$; creatinine $1.1 \mathrm{mg} / \mathrm{dL} ; \mathrm{K}^{+} 4.4 \mathrm{mEq} / \mathrm{L} ; \mathrm{Na}^{+} 138 \mathrm{mEq} / \mathrm{L} ; \mathrm{C} 3169 \mathrm{mg} /$ dL; C4 50mg/dL; negative lupus anticoagulant; albumin 2.5g/ dL. Negative viral serologies. Proteinuria 3.86g/day. An abdominal ultrasound with doppler showed normal sized kidneys, with obstruction in left renal vein, compatible with thrombosis. The patient was investigated for coagulation disturbances by the Division of Hematology and was not found to have any disturbance. A renal biopsy was performed and the histological pattern was compatible with membranous nephropathy. Initial treatment consisted in cyclophosphamide 100mg, twice a day, prednisone 15mg/ day and warfarin 10mg/day. He presented a favorable outcome, with complete remission of the manifestations.

\section{Discussion}

The incidence of thrombosis, both venous and arterial, is higher in patients with nephrotic syndrome than in the general population. ${ }^{21}$ The risk of thrombosis varies according to the type of glomerulopathy. It is higher in membranous nephropathy, followed by membranoproliferative glomerulonephritis and minimal change disease. ${ }^{22,23}$ This risk seem also to be associated with the severity of nephritic syndrome and can increase when albumin concentration falls below 2.0gm/dl 21,22,24-27. We showed two cases of renal vein thrombosis (RVT) secondary to membranous nephropathy, with complete remission after specific treatment.

The cause of hypercoagulable state in nephritic syndrome is not completely known. It is believed that antithrombin and plasminogen levels are decreased, due to urinary losses, associated with platelets activation and hyperfibrinogenemia. ${ }^{1,2}$

RVT can be uni or bilateral and can extends to inferior vena cava. The course of RVT is more frequently chronic, but acute forms, as observed in the described cases, can occurr. ${ }^{1,2}$

RVT can manifest with symptoms of renal infarction: flank pain, microhematuria, increased levels of LDH, scrotal edema and increased size kidneys. ${ }^{28}$ RVT can also be assymptomatic. In the first case, the patient did not present complaints directly associated with RVT, while the second presented characteristic lumbar pain.

The gold standard method for the diagnosis of RVT is renal venography, but less invasive procedures are more frequently used, as ultrasound with Doppler, magnetic resonance or angiotomography. ${ }^{25,29,30-34}$ We preferred to use ultrasound because of its easy accessibility and absence of risks of using contrast media, and we found positive results that confirmed the diagnosis of RVT.

Treatment of RVT consists in anticoagulation. In nephrotic syndrome there are two aspects of anticoagulation that must be left under consideration: anticoagulation to prevent thrombotic events and dissolution of thrombi with thrombolitics. $^{1,2}$

Patients with RVT should be treated as the cases of pulmonary embolism. Initially it can be done with heparin followed by warfarin. ${ }^{35}$ Some patients with nephritic syndrome can be resistant to initial anticoagulation due to decreased levels of antithrombin. Oral anticoagulation is recommended for 6 to 12 weeks and can be prolongated if the patient remains with nephrotic syndrome. 
In summary, RVT is not a common event in nephritic syndrome and it is more frequent in those with membranous nephropathy. Treatment consists in anticoagulation. Prophylaxis in high risk patients with nephritic syndrome is controversial, and further studies on this aspect are necessary.

\section{Conflict of Interest: None}

\section{References:}

1. Andrassy K, Ritz E, Bommer J. Hypercoagulability in the nephrotic syndrome. Klin Wochenschr 1980; 58: 1029-1036

2. Cade R, Spooner G, Juncos L, et al. Chronic renal vein thrombosis. Am J Med 1977; 63: 387-397

3. Chugh KS, Malik N, Uberoi HS, et al. Renal vein thrombosis in nephrotic syndrome - a prospective study and review. Postgrad Med J 1981; 57: 566-570

4. Kanfer A, Kleinknecht D, Broyer M, Josso F. Coagulation studies in 45 cases of nephrotic syndrome without uremia. Thromb Diath Haemorrh 1970; 24: 562-571

5. Kendall AG, Lohmann RC, Dossetor JB. Nephrotic syndrome. A hypercoagulable state. Arch Intern Med 1971; 127: $1021-1027$

6. Kauffmann RH, Veltkamp JJ, Van Tilburg NH, Van Es LA. Acquired antithrombin III deficiency and thrombosis in the nephrotic syndrome. Am J Med 1978; 65: 607-613

7. Kuhlmann U, Steurer J, Rhyner K, et al. Platelet aggregation and beta-thromboglobulin levels in nephrotic patients with and without thrombosis. Clin Nephrol 1981; 15: 229-235

8. Llach F, Papper S, Massry SG. The clinical spectrum of renal vein thrombosis: acute and chronic. Am J Med 1980; 69: 819-826

9. Llach F, Koffler A, Finck E, Massry SG. On the incidence of renal vein thrombosis in the nephrotic syndrome. Arch Intern Med 1977; 137: 333-336

10. Llach F, Arieff AI, Massry SG. Renal vein thrombosis and nephrotic syndrome. A prospective study of 36 adult patients. Ann Intern Med 1975; 83: 8-14

11. Trew PA, Biava CG, Jacobs RP, Hopper J Jr. Renal vein thrombosis in membranous glomerulonephropathy: incidence and association. Medicine 1978; 57: 69-82

12. Andrassy K, Oertel PJ, Mehls O, et al. Thromboembolic complications and haemostasis in the nephrotic syndromeis there a difference between children and adults? Proc Eur Dial Transplant Assoc 1982; 19: 597-601

13. Mehls O, Andrassy K, Koderisch J, et al. Hemostasis and thromboembolism in children with nephrotic syndrome: differences from adults. J Pediatr 1987; 110: 862-867
14. Lilova MI, Velkovski IG, Topalov IB. Thromboembolic complications in children with nephrotic syndrome in Bulgaria (1974-1996). Pediatr Nephrol 2000; 15: 74-78

15. Velasquez Forero F, Garcia Prugue N, Ruiz Morales N. Idiopathic nephrotic syndrome of the adult with asymptomatic thrombosis of the renal vein. Am J Nephrol 1988; 8: 457-462

16. Wagoner RD, Stanson AW, Holley KE, Winter CS. Renal vein thrombosis in idiopathic membranous glomerulopathy and nephrotic syndrome: incidence and significance. Kidney Int 1983; 23: 368-374

17. Cherng SC, Huang WS, Wang YF, et al. The role of lung scintigraphy in the diagnosis of nephrotic syndrome with pulmonary embolism. Clin Nucl Med 2000; 25: 167-172

18. Cameron JS. Coagulation and thromboembolic complications in the nephrotic syndrome. Adv Nephrol Necker Hosp 1984; 13: $75-114$

19. Kutcher R, Cohen JR, Gordon DH. Glomerulonephritis and nephrotic syndrome complicated by renal vein thrombosis and pulmonary emboli: report of two cases. Am J Roentgenol 1977; 128: 447-449

20. Singhal R, Brimble KS. Thromboembolic complications in the nephrotic syndrome: pathophysiology and clinical management. Thromb Res 2006; 118: 397-407

21. Mahmoodi BK, ten Kate MK, Waanders F et al. High absolute risks and predictors of venous and arterial thromboembolic events in patients with nephrotic syndrome: results from a large retrospective cohort study. Circulation 2008; 117: 224-230

22. Llach F, Papper S, Massry SG. The clinical spectrum of renal vein thrombosis: acute and chronic. Am J Med 1980; 69: 819-827

23. Chugh KS, Malik N, Uberoi HS et al. Renal vein thrombosis in nephrotic syndrome-a prospective study and review. Postgrad Med J 1981; 57: 566-570

24. Thom, TJ, Kannel, WB, Silbershatz, H, D’Agostino, RB. Incidence, prevalence and mortality of cardiovascular diseases in the United States. In: Hurst's The Heart, 9th ed, Alexander, RW, Schlant, RC, Fuster, V (eds), McGraw-Hill, New York 1998. p. 3

25. Singhal, R, Brimble, KS. Thromboembolic complications in the nephrotic syndrome: pathophysiology and clinical management. Thromb Res 2006; 118: 397-407

26. Cherng SC, Huang WS, Wang YF et al. The role of lung scintigraphy in the diagnosis of nephrotic syndrome with pulmonary embolism. Clin Nucl Med 2000; 25: 167-172

27. Waldman M, Crew RJ, Valeri A et al. Adult minimal-change disease: Clinical characteristics, treatment, and outcomes. Clin J Am Soc Nephrol 2007; 2: 445-453 
28. Llach, F. Hypercoagulability, renal vein thrombosis, and other thrombotic complications of nephrotic syndrome. Kidney Int 1985; 28: 429-439

29. Wei, LQ, Rong, ZK, Gui, L, Shan, RD. CT diagnosis of renal vein thrombosis in nephrotic syndrome. J Comput Assist Tomogr 1991; 15: 454-457

30. Glassock, RJ. Diagnosis and natural course of membranous nephropathy. Semin Nephrol 2003; 23: 324-332

31. Rahmouni A, Jazaerli N, Radier C et al. Evaluation of magnetic resonance imaging for the assessment of renal vein thrombosis in the nephrotic syndrome. Nephron 1994; 68: 271-272
32. Tempany CM, Morton RA, Marshall FF. MRI of the renal veins: assessment of nonneoplastic venous thrombosis. J Comput Assist Tomogr 1992; 16: 929-934

33. Avasthi, PS, Greene, ER, Scholler, C, Fowler, CR. Noninvasive diagnosis of renal vein thrombosis by ultrasonic echo-Doppler flowmetry. Kidney Int 1983; 23: 882-887

34. Platt, JF, Ellis, JH, Rubin, JM. Intrarenal arterial Doppler sonography in the detection of renal vein thrombosis of the native kidney. Am J Roentgenol 1994; 162: 1367-1370

35. Wu, CH, Ko, SF, Lee, CH et al. Successful outpatient treatment of renal vein thrombosis by low-molecular weight heparins in 3 patients with nephrotic syndrome. Clin Nephrol 2006; 65: 433-440 